\title{
Turtles all the way down: loggerheads at the root of the chelonian tree
}

\author{
Tyler Lysona and Scott F. Gilbert ${ }^{\mathrm{b}, *}$ \\ ${ }^{a}$ Department of Geology and Geophysics, Yale University, New Haven, CT, 06520 USA \\ bepartment of Biology, Swarthmore College, 500 College Avenue, Swarthmore, PA, 19081 USA \\ *Author for correspondence (email: sgilber1@ @warthmore.edu)
}

\section{INTRODUCTION}

The recent discovery of the oldest and most primitive stem turtle, Odontochelys semitestacea ( $\mathrm{Li}$ et al. 2009), from the lower Upper Triassic of China reopens the debate regarding the origin of the turtle shell, the paleoecology of basal turtles (terrestrial or aquatic), and the placement of turtles among amniotes. The debate surrounding the origin of the shell dates back to Cuvier (1800-1805) with two competing hypotheses. The de novo hypothesis, argues that the carapace (dorsal shell) formed from the outgrowth of intramembranous bone from the periost of the ribs and neurals, and this view is largely supported by developmental data on current turtles (Gilbert et al. 2001; Cebra-Thomas et al. 2005). The composite origin hypothesis argues that the shell formed largely by the fusion of overlying osteoderms with the underlying ribs, and this perspective has some histological support (Scheyer et al. 2008).

\section{SHELL FORMATION}

Joyce et al. (2009) described fragments of a 210 million-yearold turtle shell from New Mexico with upright ribs, an exceptionally thin shell, and most importantly, only a slight melding together of the underlying ribs with the boney shell. This early turtle, Chinlechelys tenertesta, seems to provide evidence for the composite hypothesis (Lee 1993; Joyce et al. 2009). However, the newly discovered and complete fossil, $O$. semitestacea, comes from slightly older $(220 \mathrm{Ma})$ strata and provides evidence for the de novo model. While $O$. semitestacea has a single row of osteoderms (called neural plates by $\mathrm{Li}$ et al. 2009) running down its midline, the carapace is otherwise devoid of osteoderms and has expanded ribs, as expected by the de novo model and the developmental mechanisms of carapace formation in current turtles.

\section{ORIGINAL PALEOECOLOGY}

The front limb proportions of $O$. semitestacea, its fully developed plastron and bridge, as well as the sedimentological data from the locality, seem to support an aquatic origin for turtles (Rieppel and Reisz 1999; Li et al. 2009). This, along with the paedomorphic appearance of $O$. semitestacea that is also found in many marine turtles, led Reisz and Head (2008) to propose that $O$. semitestacea was an early radiation of turtles into the water. However, the front limb proportions, histological data, shape of shell, poor early fossil record, and presence of osteoderms suggest that other basal turtles were terrestrial (Joyce and Gauthier 2004; Scheyer et al. 2007); and the aquatic emergence of $O$. semitestacea can be questioned by the fact that its front limb proportions indicate only a semiaquatic habitat. Regardless, given the terrestrial paleoenvironmental interpretation for other basal turtles and the contentious debate regarding the outgroup of turtles (outlined below), two outgroups with clear and congruent paleoenvironmental interpretations cannot be obtained, and thus parsimony cannot reliably be used to determine the paleoecology of basal turtles (Maddison et al. 1984).

\section{AMNIOTE POSITION}

Moreover, relationships within the reptile clade remain contentious, largely due to the disagreement over the placement of turtles with regard to the remaining reptiles, which are traditionally referred to as "diapsids" on the basis of their possession of two temporal fenestrae (Romer 1966; Benton 1985; Carroll 1988). There are two major groups of living diapsids: archosaurs (crocodiles and birds) and lepidosaurs (Sphenodon and squamates). This leaves three ways in which turtles might be related to diapsids: (1) outside a monophyletic Diapsida, or as sister group to either (2) lepidosaurs or (3) archosaurs, which would render Diapsida paraphyletic (Lee 2001). Each of these hypotheses has some support from recent morphological or molecular analyses.

Turtles as sister group to diapsids is the traditional hypothesis (Gauthier et al. 1988). This hypothesis implies that turtles retain a number of primitive amniote characters including an unfenestrated skull. Under this hypothesis, the 
nearest relative to turtles are such "anapsid" reptiles as pareiasaurs (Gregory 1946; Lee 1993, 1997), which share with turtles a consolidated braincase, a shortened vertebral column, and the presence of dermal armor (Lee 1995, 2001). Joyce et al. (2009) turtle provided evidence for an osteodermbearing ancestor that seemed most congruent with this hypothesis.

However, this traditional amniote tree has been challenged by Rieppel and deBraga, who analyzed turtles in the first comprehensive amniote phylogenetic analysis that did not assume a monophyletic Diapsida (Rieppel and deBragga 1996; deBraga and Rieppel 1997). Their analysis placed turtles within diapsids as sister group to extant lepidosaurs. More specifically, Rieppel and deBraga placed turtles as sister group to sauropterygians, a marine group consisting of placodonts, plesiosaurs, and their relatives. This implies that turtles secondarily closed their temporal fenestrae and lost their impedance-matching ear by reverting to the basal amniote condition. Putative synapomorphies for this topology include a hooked fifth metatarsal and an astragalus-calcaneum complex (deBraga and Rieppel 1997; Rieppel and Reisz 1999). Rieppel and Reisz (1999) hypothesized the ancestral turtle had a marine origin, that it likely had dorsally located ribs, and that its plastron (presumably derived from gastralia) developed first in order to protect their soft underbelly from predators. This evolutionary scenario is supported by the $\mathrm{Li}$ et al. (2009) article, in which Rieppel is a co-author.

However, anatomical evidence may be misleading, especially if there were widespread adaptive convergence as suggested by Hedges and Poling (1999). Indeed, there appear to be conflicting signals within the morphologic dataset. While there are several cranial characters that suggest a basal anapsid affinity for turtles, there are several appendicular characters that suggest a diapsid affinity (Lee et al. 2008). And while there is controversy concerning the homology of some appendicular characters (i.e., presence/absence of acromion or cleithra) and over the character coding of fossil turtles (see Lee 2001), the current morphological matrices appear to have two signals: either the turtles are sister group to all diapsids, or they are within the diapsids as a sister group to lepidosaurs.

Molecular phylogenetic analyses have not solved the debate. Indeed, both mitochondrial and nuclear gene analyses contradict both morphological hypotheses, consistently suggesting that turtles are related to archosaurian diapsids (Wilkinson et al. 1997; Zardoya and Meyer 1998; Hedges and Poling 1999; Kumazawa and Nishida 1999; Janke et al. 2001; Meyer and Zardoya 2003; Rest et al. 2003; Hugall et al. 2007). One thing the rival paleontological groups have agreed upon is that this hypothesis has virtually no morphologic support (Rieppel 2000; Lee 2001).

Although early molecular analyses could be criticized for having short sequences, poor taxon sampling, or using genes with inappropriately fast substitution rates, more recent mo- lecular analyses of long nuclear genes continue to place turtles within Diapsida as sister group to archosaurs. Hugall et al. (2007) analyzed the nuclear gene RAG-1 across 88 taxa. The aligned sequence was 3297 sites. Both the parsimony and Bayesian phylogenetic analyses strongly supported the placement of turtles as sister group to archosaurs. The bootstrap value for this node was $99 \%$ and the Bremer support was 17 . The posterior probability in the Bayesian analysis was $100 \%$. In their discussion, Hugall et al. (2007) point out that this arrangement needs to be more rigorously analyzed for two reasons: (1) there is no morphologic support for turtles sister group to archosaurs, and (2) there are nucleotide substitution rate differences between turtles and diapsid reptiles due to the extreme slowdown in the rate found in turtles. This slow molecular evolutionary rate in turtles might predispose the reptile RAG-1 tree to be rooted within diapsids (Hugall et al. 2007). However, turtles do not have a slow rate in mitochondrial genes (Rest et al. 2003) and these studies continue to place turtles as sister group to archosaurs (Lee et al. 2008).

The new discovery of the beautifully preserved fossil $O$. semitestacea produces more questions than it answers, reopening questions of turtle origins, shell evolution, and original paleoecology. A solution to these problems will have to wait for additional fossil material and a unification of morphological, developmental, and molecular data that can support one hypothesis to the exclusion of others.

\section{REFERENCES}

Benton, M. J. 1985. Classification and phylogeny of the diapsid reptiles. Zool. J. Linn. Soc. 84: 97-164.

Carroll, R. L. 1988. Vertebrate Paleontology and Evolution. W. H. Freeman, New York.

Cebra-Thomas, J., et al. 2005. How the turtle forms its shell: a paracrine hypothesis of carapace formation. J. Exp. Zool. B. 304: 558-569.

Cuvier, G. 1800-1805. Leçons d'anatomie comparée; recueillies et publiées sous les yeux de l'Auteur, par MM. C. Duméril et G. L. Duvernoy Tome 1-5. Paris, France: Baudouin chez Fuchs.

DeBraga, M., and Rieppel, O. 1997. Reptile phylogeny and the affinities of turtles. Zool. J. Linn. Soc. 120: 281-354.

Gauthier, J., Kluge, A. G., and Rowe, T. 1988. Amniote phylogeny and the importance of fossils. Cladistics 4: 105-209.

Gilbert, S. F., Loredo, G. A., Brukman, A., and Burke, A. C. 2001. Morphogenesis of the turtle shell: the development of a novel structure in tetrapod evolution. Evol. Dev. 3: 47-58. (doi: 10.1046/j.1525-142x. 2001.003002047.x).

Gregory, W. K. 1946. Pareiasaurs versus placodonts as near ancestors to the turtles. Bull. Am. Mus. Nat. Hist. 86: 275-326.

Hedges, S. B., and Poling, L. L. 1999. A molecular phylogeny of reptiles. Science 283: 998-1001.

Hugall, A. F., Foster, R., and Lee, M. S. Y. 2007. Calibration choice, rate smoothing, and the pattern of tetrapod diversification according to the long nuclear gene RAG-1. Syst. Biol. 56: 543-563.

Janke, A. D., Erpenbeck, D., Nilsson, M., and Arnason, U. 2001. The mitochondrial genomes of the iguana (Iguana iguana) and the caiman (Caiman crocodylus): implications for amniote phylogeny. Proc. R. Soc. B 268: 623-631.

Joyce, W. G., and Gauthier, J. A. 2004. Palaeoecology of Triassic stem turtles sheds new light on turtle origins. Proc. R. Soc. B 271: 1-5. (doi: 10.1098/rspb.2003.2523). 
Joyce, W. G., Lucas, S. G., Scheyer, T. M., Heckert, A. B., and Hunt, A. P. 2009. A thin-shelled reptile from the Late Triassic of North America and the origin of the turtle shell. Proc. R. Soc. B. 276: 507-513.

Kumazawa, Y., and Nishida, M. 1999. Complete mitochondrial DNA sequences of the green turtle and blue-tailed mole skink: statistical evidence for archosaurian affinity of turtles. Mol. Biol. Evol. 16: 784-792.

Lee, M. S. Y. 1993. The origin of the turtle body plan: bridging a famous morphological gap. Science 261: 1716-1720.

Lee, M. S. Y. 1995. Historical burden in systematics and interrelationships of "parareptiles". Biol. Rev. 70: 447-459.

Lee, M. S. Y. 1997. Reptile relationships turn turtle. Nature 389: 245-246.

Lee, M. S. Y. 2001. Molecules, morphology, and the monophyly of diapsid reptiles. Contrib. Zool. 70: 121-138.

Lee, M. S. Y., Reeder, T. W., Slowinski, J. B., and Lawson, R. 2008. Resolving reptile relationships: molecular and morphological markers. In J. Cracraft and M. J. Donoghue (eds.) Assembling the Tree of Life. Oxford University Press, New York, pp. 451-467.

Li, C., Wu, X.-C., Rieppel, O., Wang, L.-T., and Zhao, L.-J. 2009. Ancestral turtle from the late Triassic of southwestern China. Nature 456: 497-501.

Maddison, W. P., Donogue, M. J., and Maddison, P. R. 1984. Outgroup analysis and parsimony. Syst. Zool. 33: 83-103.

Meyer, A., and Zardoya, R. 2003. Recent advances in the (molecular) phylogeny of vertebrates. Ann. Rev. Ecol. Syst. 34: 311-338.
Reisz, R., and Head, J. J. 2008. Turtle origins out to sea. Nature 456: 450451.

Rest, J. S., et al. 2003. Molecular systematics of primary reptilian lineages and the tuatara mitochondrial genome. Mol. Phylogenet. Evol. 29: 289297.

Rieppel, O. 2000. Turtles as diapsid reptiles. Zool. Scr. 29: 199-212.

Rieppel, O., and deBragga, M. 1996. Turtles as diapsid reptiles. Nature 384 453-455.

Rieppel, O., and Reisz, R. 1999. The origin and evolution of turtles. Аnпи. Rev. Ecol. Syst. 30: 1-22.

Romer, A. S. 1966. Vertebrate Paleontology. 3rd Ed. University of Chicago Press, Chicago.

Scheyer, T. M., Brüllmann, B., and Sánchez-Villagra, M. R. 2008. The ontogeny of the shell in side-necked turtles, with emphasis on the homologies of costal and neural bones. J. Morphol. 269: 1008-1021.

Scheyer, T. M., Sander, P. M., Joyce, W. G., Böhme, W., and Witzel, U. 2007. A plywodd structure in the shell of fossil and living soft-shelled turtles (Trionychidae) and its evolutionary implications. Org. Divers. Evol. 7: 136-144.

Wilkinson, M., Thorley, J., and Benton, M. J. 1997. Uncertain turtle relationships. Nature 387: 466.

Zardoya, R., and Meyer, A. 1998. Complete mitochondrial genome indicates diapsid affinities of turtles. Proc. Natl. Acad. Sci. USA 95: 1422614231. 